*This article has been accepted for publication in the journal Political Quarterly.*

\title{
NHS inquiries and the problem of culture
}

\begin{abstract}
If inquiries are about learning the lessons of the past, why do they appear to find the same failings time and again? Bristol, Mid Staffordshire, Morecambe Bay, Liverpool Community Health are all examples of where culture went wrong. The lack of learning from inquiries is a prominent concern and one raised elsewhere in this issue. In this article, I explore why it might be that culture is repeatedly found to be the cause of healthcare failures. I start by reviewing perspectives on what culture is and the degree to which it is possible change it. I examine how culture was described in the Bristol, Mid Staffordshire, Morecambe Bay and Liverpool inquiries and question whether these are the same cultures with the same problems or whether they are different. I discuss possible explanations for apparent similarities, describe how cultural change occurs and conclude by drawing out the implications of focusing on culture as a threat to patient safety.
\end{abstract}

Keywords: inquiries, healthcare failures, safety, culture, cultural change

\section{Introduction}

It is widely held that inquiries are a means of learning the lessons of the past, with the requirement to make recommendations on the lessons to be learned for the wider NHS even being written into the inquiry's terms of reference ${ }^{1}$. Yet, questions are repeatedly raised about whether inquiries do actually fulfil this aim as there appears to be a recurrence of the same themes over subsequent inquiries. A number of inquiries over the last two decades have identified culture to be the cause of healthcare failures, suggesting that despite considerable investment of time, money and expertise, effectively tackling the problem of culture is yet to be solved. So where does the problem lie? In this article, I explore what culture is, why it is considered so problematic, and the degree to which we can change it. I review how culture featured in Bristol, Mid Staffordshire, Morecambe Bay and Liverpool inquiries and explore some of their similarities and differences, before giving an example of where there has been cultural change and highlighting the factors that have shaped this change.

\section{The problem with culture}

The problem with culture would seem to be threefold. First, there is a widespread lack of consensus about the precise meaning of culture. Different academic disciplines tend to understand culture in different ways which creates ambiguity and confusion, but it also affects the way the concept is put to use in these different disciplines ${ }^{2}$. Second, there is also a general dissatisfaction with existing approaches to managing cultural change, and impatience with the lack of progress we appear to have made. The Report of the Mid Staffordshire NHS Foundation Trust Public Inquiry, was followed by criticism that recommendations about cultural change were 'somewhat aspirational and broad brush's ${ }^{3}$. 
*This article has been accepted for publication in the journal Political Quarterly.*

Although the focus for much of the criticism around cultural change, it is fair to say that both before and after this report, the process of cultural change has been poorly understood. Indeed, there are competing claims from different academic disciplines over whether it is even possible to manipulate organisational cultures to beneficial effect. Finally, it is widely understood that cultures are resistant to change because they are deeply ingrained in local day-to-day systems and practices as well as being related to wider social conditions ${ }^{4}$. Further reasons for this resistance to change include the inequalities in power and authority, and competing sets of legitimate interests within organisations ${ }^{5}$. Inequalities in power are relevant in that attempts at change often focus on the attitudes and behaviours of individuals at the lowest level of a hierarchy - frontline staff - and thus on those with the least capacity to implement change. Moreover, while frontline staff hold a great deal of safety-critical know-how, they are often unable to persuade those higher up the hierarchy of the credibility or relevance of their knowledge ${ }^{6}$. Competing sets of legitimate interests come into play when, for example, new ways of managing quality and safety interfere with established ways healthcare professionals deal with risk, ways that reflect their respective knowledge and status ${ }^{7}$.

Given that culture is a complex concept that is understood in different ways, it is necessary to look briefly at the most common understandings of culture as this is where part of the problem lies; how culture is conceptualised relates to expectations of whether or not it is possible to manipulate it. The most common way of defining culture in healthcare-related fields is as the prevailing beliefs, values, assumptions and attitudes of a community, and their translation into patterns of behavior, organisational routines and rituals. This definition focuses on the tacit knowledge - assumptions, values and beliefs - of a community and how that informs people's behaviours, implying a linear relationship from values and beliefs to behaviours. Culture is often said to operate at different levels, from artefacts as visible manifestations of culture, through shared beliefs and values used to justify behaviours, to shared, but largely unconscious, expectations and assumptions that underpin day-to-day activities ${ }^{8}$. In anthropology, culture is understood as the shared, overt and covert understandings that constitute conventions and practices, and the ideas, symbols, and concrete artifacts that sustain conventions and practices, and make them meaningful. ${ }^{\prime 9}$. This definition includes tacit understandings (as well as explicit) but places more emphasis on how those understandings become manifested in 'concrete artifacts' such as policies and technologies that then sustain practices. This suggests a relationship between knowledge (tacit and explicit), systems and practices that is mutually constitutive, rather than one (knowledge) preceding the other (systems and practices). Culture, then, is both a product and context of social action.

A point of confusion arises from the emphasis definitions of culture have placed on the shared understandings, values, practices and so forth. In a large organisation, just how widely are such values shared? Even within a ward, there are a number of different professional groupings and these may hold different values, or the same values to different degrees. Mannion and Davies have described hospitals as 'a dynamic cultural mosaic made up of multiple, complex, and overlapping subgroups with variably shared assumptions, values, beliefs and behaviours' 10 . Hospital cultures, therefore, are not uniform across the organisation and encompasses complex links between attitudes, identities and ideas about professionalism. 
*This article has been accepted for publication in the journal Political Quarterly.*

And as mentioned above, there are different perspectives on whether it is possible to manipulate cultures with predictable and beneficial effects. Anthropologist, Clifford Geertz $^{11}$ insists that 'culture is not a power, something to which social events, behaviors, institutions, or processes can be causally attributed; it is a context, something within which they can be intelligibly - that is, thickly - described'. Here, culture is an analytical perspective, something that lends actions intelligibility and meaning. Accordingly, sociology and anthropology have tended to conceptualise culture as a tool for social analysis, whereas organisational, engineering and human factors disciplines have tended to conceptualise it more as a concrete world of beliefs and practices associated with a particular group ${ }^{12}$ and thus something potentially amenable to intervention. With this debate in mind, I now explore how cultures are described in the various inquiry reports.

\section{'Culture' in NHS inquiries}

What I present below is a distillation of the cultures described in the reports. All the reports gave detailed descriptions of practices and the manner in which they were carried out, but these were by no means uniformly enacted by all - some people resisted these practices, some raised complaints. Nevertheless, a sense of the prevailing cultures emerges and it is this I seek to convey.

The inquiry that followed events at Bristol Royal Infirmary found the existence of a 'club culture'. This operated largely at the managerial/board levels and entry to the club was dependent on length of service and 'fit' with the executive team. The Chief Executive made the final decision on who became a clinical director from among senior clinicians with whom he had worked for many years. Challenges to this policy were perceived as disloyalty. It resulted in all the decision-making power being held by too few individuals. Exacerbating this imbalance of power was the preference for oral communication which meant that those who were outside the 'club' were unable to trace decisions. There was a rigid distinction between clinical and managerial matters and one which prioritised 'clinical freedom'. The Chief Executive saw his role as freeing up clinicians to do their job at the bedside and it was not for managers to interfere. Likewise, managers did the managing which meant that it was difficult for clinicians to raise concerns if they did not belong to the 'club'. There was also a paternalistic attitude towards patients, one which sought to 'protect' parents from too much information. And teamwork was problematic in that teams were 'profoundly hierarchical' and made up of single disciplines such as surgeons, anaesthetists or nurses, rather than being multidisciplinary and arranged around patient care.

At Mid Staffordshire there was an 'insidious negative culture involving a tolerance of poor standards and a disengagement from managerial and leadership responsibilities'. There was an overwhelming emphasis on finances and achieving Foundation Trust status, and inadequate staffing (particularly of nurses) arising from workforce reductions employed to meet financial targets. This resulted in a lack of basic care and tolerance of poor standards due to the gradual corrosive effect of working in such difficult environments. Many of those giving testimony to the inquiry emphasised that such tolerance resulted from severely inadequate staffing over a protracted length of time and that staff would regularly work beyond their hours, unpaid, in an attempt to provide adequate care. There was bullying, 
*This article has been accepted for publication in the journal Political Quarterly.*

fear of adverse repercussions and low morale with examples of nurses emerging from bed management meetings in tears for fear of losing their jobs. Consultant staff became disengaged from managerial decision-making due to the perception that the raising of concerns was not welcome by senior management, and that to do so would risk job security. Moreover, when concerns were raised, the response was generally defensive of the Trust leadership's position; it was characterised as one of 'immovability' and often accompanied by the platitude that things would improve once foundation trust status had been attained. This led to resignation on the part of the clinicians. Finally, there was a lack of urgency about remedying problems even when they were recognised.

At Morecambe Bay there was a significant degree of tribalism between different staff groups, with the working relationships between the midwives, obstetricians and paediatricians being insular, disengaged, and characterised by an unwillingness to collaborate. Midwives almost exclusively controlled risk assessment procedures for pregnant women and zealously pursued the concept of 'normal birth', even on some occasions turning away obstetricians when it was clear that problems had developed during delivery. The reluctance to collaborate exacerbated the effects of poor clinical knowledge and resulted in poor clinical decisions; obstetricians delivered babies of high-risk mothers in the unit (rather than transferring them before birth to better equipped clinical settings) against the advice of the paediatricians. Paediatricians, however, were also unwilling to transfer babies to other clinical settings; they adopted a 'wait and see' approach with babies likely to need neonatal intensive care, missing the optimal time for transfer and necessitating difficult emergency transfers. The isolation of the maternity unit played a role in that, because of its relatively remote location, it was difficult to recruit medical staff and many of the non-medical staff had trained th the hospital and worked there ever since. This isolation allowed practice to become detached from the standards and procedures found elsewhere. Governance procedures, particularly internal investigations into untoward incidents, were inadequate and overly protective of the midwives, often being conducted by the maternity risk manager who combined the role with that of a supervisor of midwives - a conflict of interest that was unacknowledged prior to the inquiry.

\section{Same or different cultures?}

Are these the same cultures, with the same problems? Should the warning signs have been recognised? Or are they different? From my perspective, culture is problematic in each of these places, but it is problematic in different ways. However, at a certain level of abstraction, points of contact can be found: poor teamwork resulted in poor clinical decisions at Bristol and Morecambe Bay. However, at Bristol, the discord was largely between clinicians in managerial positions and clinicians more generally, in that if you were not in the small number of people with power, your concerns would not be heard. And the main point of contest was around whether particular surgeons were skilled enough to perform particular operations or whether that service should move elsewhere. At Morecambe Bay, non-collaboration was a feature of daily clinical practice in that the midwives, obstetricians and paediatricians could not work together and sought to avoid doing so wherever possible. 
*This article has been accepted for publication in the journal Political Quarterly.*

Hierarchy was also an issue at Bristol and Morecambe Bay. At Bristol there existed a traditional hierarchical relationship between different staff groups with surgeons at the pinnacle, but the deference involved in the traditional arrangement was positively resisted, 20-30 years later, by the midwives at Morecambe Bay to the point that they actively excluded the obstetricians on occasions. In each of these situations, professional self-image worked against teamwork but the way this is manifested in each situation - a complete lack of challenge at Bristol and overt interprofessional challenge at Morecambe Bay - is so different that it is unlikely staff would identify themselves as exhibiting the same problems.

There are also connections to be found between Bristol and Mid Staffordshire in that senior clinical staff were disengaged from managerial decision-making in both locations but this came about in different ways. At Bristol, there was no process of engaging senior clinical staff in decision-making, effectively excluding them from those forums, and no expectation that anyone else should be involved (the clinical/managerial distinction). At Mid Staffordshire, processes for consultation existed but the problem was one of apathy brought about by repeatedly raising concerns to a management that was immovable.

Consequently, these cultures bear some similarity - at a conceptual level - but also many differences in the way problematic aspects of culture have come about and the particular formation they take, and this makes it more difficult for individuals to recognise themselves as exhibiting the same problems as described in earlier inquiries. Why then are similarities so apparent when viewed from the outside? One reason is that during the inquiry process particular events and practices are extracted out of day-to-day activity. They are described in sharp focus whereas for the healthcare managers and professionals involved, these events are embedded within the blur of daily activity. Another reason similarities between different organisational failures are emphasised is because the interpretation and presentation of findings are informed by current understandings of organisational failure which provide the concepts and frameworks for explaining failure. That investigations of patient harms are conducted in the light of the most up-to-date knowledge of the causes of such harm is of course desirable. What this does, however, is highlight certain aspects of the situation and describe them in similar terms using the language and theories of safety science. The way failure is explained then, has a homogenising effect, particularly when the detailed investigations get distilled into key messages, bullet points and news headlines. The point is that talking in general terms of 'culture' is too simplistic; it erases complexity, highlights similarities and downplays differences. But downplaying differences between sites means that warning signs appear more obvious, self-evident even, to an external point of view.

There are, however, occasions when failures of care resonate so strongly with a previous case that it would seem their similarities cannot be accounted for only by the above explanations. This was indeed the case with Liverpool Community Health Trust. Here, there was an intolerant and bullying leadership culture. Inexperience of the leadership and an overly ambitious cost-improvement programme aimed at attaining foundation trust status led to 'a culture of intolerance, disbelief and fear, with a clear lack of care for the workforce.' This focus on financial savings resulted in dramatic reductions in frontline staff and an inability to deliver care to a sufficient and safe standard. The response to safety incidents was bullying and resistant to the suggestion of an underlying cause connected 
*This article has been accepted for publication in the journal Political Quarterly.*

with staffing levels. Meetings were conducted in an intimidating and bullying manner that involved addressing staff inappropriately by shouting and finger-pointing, and staff felt blamed for incidents that occurred. When staff raised concerns, there were repeated accounts of staff being suspended without being told why, or what the next steps would be. In some cases, these suspensions lasted for many months without any apparent process for resolution. This contributed significantly to a climate of fear and insecurity among Trust staff.

The similarities with Mid Staffordshire are undeniable, at least at the leadership and managerial levels. However, one does not get the same sense of tolerance of poor standards as at Mid Staffordshire, quite the opposite. On reading the report, it seems as though front-line staff do not share the leadership culture at all, one gets a sense that if only the leadership would change, frontline staff would feel enormous relief at the prospect of once again being able to practise safely. Although similar in nature, the problems at Liverpool Community Health Trust come across as more extreme than at Mid Staffordshire: the cost improvement programmes even more ambitious, the willingness of the leadership to bully and intimidate more overt, denial that the cause of the problems had anything to do with cuts in resources and shortage of appropriately trained staff more absolute, and the deleterious effects this had on staff well-being more palpable. So, in this case the warning signs were recognisable and it would seem that staff did so: they could clearly see the shortcomings in the care they delivered and suffered the effects of having to work in these exceedingly difficult circumstances. Here, staff did attempt to resist the leadership culture and to raise concerns, but they were effectively suppressed by a significant level of bullying, intimidation and harassment. Therefore, if the warning signs were recognised but changing the situation was not possible, this returns us to the question of how cultural change occurs.

\section{Cultural Change}

As mentioned above, it is widely acknowledged that cultures are difficult to change as they are deeply connected with both day-to-day systems and practices within a workplace but also tied to external bodies (such as professional bodies and the standards and guidelines they set), as well as being related to wider social conditions such as policy contexts and societal expectations of healthcare. However, this perspective does not convey culture entirely accurately. It suggests that culture is immovable and yet, these things, both inside and outside the workplace, are continually evolving, in small, incremental and diffuse ways. There is staff turnover, local policies get updated, new technologies are introduced, leaderships change, new professional guidance is issued, political and policy contexts shift and as do societal expectations. Culture is a product of all these things, so in this sense, culture is changing all the time. However, these things do not necessarily change at the same time or rate, and so the things that are slower to change can seem to anchor certain elements of culture in place.

I would like to briefly give an example of where I think there has been cultural change. At Bristol, care was based on a paternalistic approach to families and the support they needed. There was the impression that informing parents and gaining their consent to treatment was regarded as a chore by the surgeons and that 'the prevailing view was that parents should be protected from too much information. ${ }^{13}$ Consequently, in the report it was 
*This article has been accepted for publication in the journal Political Quarterly.*

suggested that healthcare should be based on partnership rather than paternalism and that patients should be involved wherever possible in decisions about their treatment and care.

With one caveat, discussed below, the paternalism found at Bristol does not feature in the descriptions of culture in any of the subsequent inquiries. I am not suggesting paternalism no longer exists in medicine, but that it exists to a much lesser degree than it did. Yet, important though the Bristol inquiry was, the recommendations were not the only spur towards a cultural shift away from paternalism. There has been movement on a number of levels both inside and outside medical practice; there was a growing appreciation within medicine about the need for shared decision-making and evolving professional guidance reflects this. But the time period covered by the inquiry (1984-1995) was a time when the internet was in its infancy and yet to transform the landscape of health information. Since then, access to health information and expectations that patients would consult sources other than healthcare professionals have changed dramatically. Although increasing health literacy may be unevenly distributed and difficult to achieve for some, there has nevertheless been a cultural shift in the level of understanding expected of and by patients towards being more informed. Thus, culture can and does change over time, but it may be that changes are required both inside and outside of an organisation and this can be difficult to control.

However, the caveat mentioned above, relates to whether the midwives' actions at Morecambe Bay can be considered paternalistic. Although not described as paternalism in the inquiry report, Dr Kirkup points out (personal communication) that the dismissal of patient and family concerns and the insistence on normal birth demonstrates an authoritative attitude characteristic of paternalism. Perhaps there has not been such movement on paternalism after all when midwives, who understood themselves to be upholding the philosophy of normal birth and protecting patients from the harm associated with unnecessarily medicalised births, overrule patients and commit alternative harms. Although, it should be noted that Morecambe Bay is possibly peculiar in the extent to which this stance was adopted. Indeed, it was stated that the isolation of the maternity unit played a role in its failure to keep pace with the standards and practices of midwifery units elsewhere.

Despite the lingering legacy of paternalism, culture can still be said to have changed when midwives adopt problematic characteristics previously associated with doctors. This raises a further problematic issue about cultural change - that the direction of change is difficult to control. Studies have shown that interventions have unanticipated - and sometimes counterproductive - effects ${ }^{14}$. Accordingly, there is a growing body of sociological work that questions the assumption that culture will respond in predictable ways to intervention.

Hillman and colleagues ${ }^{15}$, for example, illustrate how the implementation of a falls reduction target on an elderly care ward unintentionally created 'a culture of restriction and limitation where patients were encouraged to remain in their chairs and use bedpans or commodes rather than be helped to a toilet'; a culture that undermined the independence, dignity and well-being of patients rather than serving it.

In line with the tendency in healthcare to define culture in terms of the values, beliefs and attitudes of groups of people, as discussed above, much of the focus for cultural change has 
*This article has been accepted for publication in the journal Political Quarterly.*

been on the values and attitudes held by staff. Use of a cultural assessment tool to give a measure of performance for benchmarking and planning of quality improvement was amongst the recommendations put forward in the Report of the Mid Staffordshire NHS Foundation Trust Public Inquiry. However, there are questions about the sensitivity of such tools to measure change ${ }^{16}$ and reservations more generally about the effectiveness of interventions that encourage people to think and feel differently ${ }^{17}$. Moreover, culture is not uniform across an organisation and the values staff hold do not map neatly onto practices; the case of Liverpool Community Health Trust, discussed above, vividly demonstrates the distress staff suffered when the leadership culture forced them to practise in ways they knew were damaging to patients.

It may be necessary to relinquish the attempt to fix culture as if it were an independent variable and to accept incomplete control in the direction of cultural change.

Conceptualising culture as a thing in itself is unhelpful when it depends on and is shaped by many factors, both inside and outside the workplace, and over which workers, managers and organisations may have little control. It was suggested in the Kennedy Report that problems 'should be seen as responses to circumstances. Change the circumstance and there is the prospect of resolution.' On the basis of the foregoing discussion, this would seem to be a more fruitful approach. Rather than thinking about culture as a whole, it may be better to identify certain problematic elements of practice, and to focus on changing the circumstances that produce these practices, ascertaining and resolving the factors that anchor them in place, for example, competing priorities or tribal interdisciplinary working relationships. Changing the constituent parts of culture will result in cultural change but large-scale, visible shifts can take many years and may need to be accompanied by broader professional, political, technological or societal change. Moreover, any attempt at change is likely to have unintended consequences as well as, or in place of, those changes that were anticipated and so changes to practices should be accompanied by evaluations of the productive and counterproductive effects they have produced.

\section{Conclusion}

What does it do to talk about culture? Introducing culture into theories of explanation for organisational failure has provided a vocabulary to talk about the manner in which practices happen, to describe how they happen and to appreciate the effects this has. As at Liverpool, for example, there were designated meetings in which to discuss safety issues, but the interrogation, blame, and finger pointing without any acknowledgement that the problem was due to inadequate staffing, meant this forum was to be avoided if possible and ineffective at improving safety when it was used. Talking about culture also gives us an understanding of the degree to which the manner of approaching issues is shared across the organisation - not uniformly but widely. Therefore, it has helped to shift the emphasis from identifying individuals who do wrong to practices in which many people are implicated, and to exploring the context for those practices.

Nevertheless, when we talk about culture in broad terms, and lose the detail and the context, this foregrounds similarities and differences are pushed to the background. Using the same language, concepts and frameworks for explanation has a homogenising effect, conveying the message that it is the same problem over and again. This is not an entirely 
negative effect as it helps to galvanise the need for action, and in this way inquiry reports can capture the zeitgeist; crystallising the prevailing mood of the time and helping to stimulate change. However, presenting different events as the same does an injustice to people working in those environments as it makes warning signs and corresponding action seem more obvious. It also does disservice to the inquiry process in that questions are repeatedly raised about the need for such lengthy, detailed and expensive proceedings when they seem to result in the same findings. Moreover, seeing each inquiry as a repeat of the last carries the risk of missing opportunities to learn more specific lessons arising from the different inquiries.

Finally, talking about culture as it has featured in these different inquiries is helping to develop an understanding of cultural change as a gradual, emergent and reflexive process of changes to practice and context. Culture is not an independent variable that responds in predictable ways to intervention, so it cannot be managed as such. Appreciating the complexity of the task means accepting incomplete control, but it does not mean we have no control. The focus should shift towards changing the circumstances, practices, policies and priorities that can be changed, and less on the values of staff hold (as the relationship between values and practices is not straightforward). Cultural change will follow, indeed culture is continually evolving, the challenge lies in identifying and changing the aspects of practice (policies, people, resources, regulations, professional guidance and so forth) that anchor negative cultures in place, and allowing time for change to become visible.

\footnotetext{
${ }^{1}$ Kennedy I. The Report of the Public Inquiry into children's heart Surgery at the Bristol Royal Infirmary 19841995: Learning from Bristol. 2001.

Francis R. Report of the Mid Staffordshire NHS Foundation Trust Public Inquiry: Executive Summary. 2013.

Kirkup B. The Report of the Morecambe Bay Investigation. 2015.

Kirkup B. Report of the Liverpool Community Health Independent Review. 2018.

2 Silbey SS. Taming prometheus: Talk about safety and culture. Annual Review of Sociology, vol 35, 2009, pp 341-69.

${ }^{3}$ Davies HTO, Mannion R. Will prescriptions for cultural change improve the NHS? BMJ, vol 346, 2013.

${ }^{4}$ Waring J. What safety-II might learn from the socio-cultural critique of safety-I. In: Hollnagel E, Braithwaite J, Wears RL, editors. Resilient Health Care. Ashgate Publishing Ltd; 2013. p. 39-48.

${ }^{5}$ Silby, Taming prometheus.

${ }^{6}$ Ibid.

${ }^{7}$ Waring, What safety-II might learn.

${ }^{8}$ Mannion R, Davies H. Understanding organisational culture for healthcare quality improvement. BMJ, vol 363. 2018.

${ }^{9}$ Napier AD, Ancarno C, Butler B, Calabrese J, Chater A, Chatterjee H, et al. Culture and health. Lancet, vol 384, no 9954, 2014, pp 1607-39.

${ }^{10}$ Manion and Davies, Understanding organisational culture.

${ }^{11}$ Geertz C. The Interpretation of Cultures. Basic Books Inc; 1973. p14

12 Silby, Taming Prometheus.

${ }^{13}$ Kennedy, Bristol Royal Infirmary Report.

${ }^{14}$ Silby, Taming Prometheus, and Davies and Mannion, Prescriptions for cultural change.

${ }^{15}$ Hillman A, Tadd W, Calnan S, Calnan M, Bayer A, Read S. Risk, governance and the experience of care. Sociology of Health and IIIness, vol 35, no 6, 2013, pp 939-55.

${ }^{16}$ Morello RT, Lowthian JA, Barker AL, McGinnes R, Dunt D, Brand C. Strategies for improving patient safety culture in hospitals: a systematic review. BMJ Quality \& Safety, vol 22, no 1, 2013, pp 11-8.

${ }^{17}$ Davies and Mannion, Prescriptions for cultural change.
} 